\title{
Agricultural development using digital technologies
}

\author{
D. A. Mustashkina ${ }^{1, *}, N . V$. Karpova $^{2}, A . S$. Makarov $^{2}$, and $M . M$. Khannanov $^{3}$ \\ ${ }^{1}$ Kazan Cooperative Institute, Branch of Russian University of Cooperation, 420081 Kazan, Russia \\ ${ }^{2}$ Kazan State Academy of Veterinary Medicine named after N.E. Bauman, 420029 Kazan, Russia \\ ${ }^{3}$ Kazan State Agrarian University, 420015 Kazan, Russia
}

\begin{abstract}
The article discusses the need for digitalization of agricultural production, which will significantly increase labor productivity, as well as competitiveness in agricultural production in Russia. The efficiency of agricultural production management using information systems based on geoinformation technologies allows reducing or completely eliminating downtime in the event of a shortage of personnel or equipment, reducing the cost of agrotechnical operations per unit of cultivated area and improving yield indicators. The digitalization of agricultural production in the Russian Federation should ensure an increase in crop and livestock production by 2025 up to 1.5 times, improve the quality of products, reduce the labor intensity of agricultural production by 1.5 times, reduce costs and prices - reduce energy and materials consumption, import dependence of agricultural machinery, their hardware and software, the advancement of automation, robotization, intelligent machine technology.
\end{abstract}

\section{Introduction}

Digital technologies of agriculture are necessary to increase the efficiency and sustainability of its functioning by cardinal changes in the quality of management of technological processes, decisionmaking at all levels of the hierarchy based on modern methods of production and further use of information on the state and forecasting possible changes in controlled elements and subsystems, as well as economic conditions in agriculture. The level of development of digitalization of agricultural production in the modern world plays a decisive role in the country's competitiveness as a driving force of economic growth.

World practice and the experience of successful domestic agricultural producers show that the use of modern digital technologies makes it possible to form optimal soil-agrotechnical and organizational-territorial conditions that provide agricultural products throughout the entire life cycle [1].

A significant increase in productivity and labor productivity, a decrease in material costs for fuels and lubricants, electricity, plant protection products, wages and other types of costs, preservation of soil fertility and environmental protection. However, due to the long absence of conditions for investment, the low level of provision with modern information technologies, domestic producers of agricultural products and foodstuffs lag behind agricultural producers in countries with traditionally developed agriculture.

In modernization, the main factors of economic activity in agricultural production are digital technologies, which allow, in comparison with traditional forms of management, to significantly increase the efficiency and quality in the production of goods, works and services. Those countries have a competitive advantage, the economy of which is based on the most advanced digital technologies.

\section{Materials and methods}

Opportunities for the modernization of the industry are enormous, the country's food security and the development of export potential are turning agriculture into a high-tech industry capable of not only providing food for itself, but also for many countries of the world, as well as creating opportunities for introducing new innovative developments that did not exist before, stimulating the adoption of management solutions that can provide the population with high-quality and safe products [2].

To achieve these objectives, the state program "Development of agriculture and regulation of markets for agricultural products, raw materials and foodstuffs" by the Decree of the Government of the Russian Federation dated February 8, 2019 No. 98 included the departmental project "Digital Agriculture" in the subprogram "Providing conditions for the development of the agro-industrial complex".

The goal of this project is to introduce digital technologies and platform solutions in agriculture, which is designed for 2019-2024. Within the framework of the main project, it is planned to implement several subprojects - this is the creation of a central information and analytical system for agriculture, which is an

\footnotetext{
*Corresponding author: daniya56@ mail.ru
} 
information bank that unites information resources in three blocks: land, livestock and equipment.

The first block is based on the use of a unified federal information system of agricultural lands. Its purpose is to obtain objective and reliable information about lands, their accounting, displaying the results of state monitoring, allows you to track the current state and actual use of lands. It is also the basis of information support for subsidizing agricultural producers. The "Smart Contract" subprogram involves the development of an intelligent support system for farmers to simplify the process of obtaining state support (subsidies, loans, insurance).

The agricultural digitalization program should provide participants with the opportunity to use broadband, mobile, LPWAN communications, information technologies of domestic instrument making, a traceability system for export-import flows of agricultural products and an electronic educational platform for training specialists of agricultural organizations to work with new technologies.

\section{Results}

According to the government program "Digital Economy of the Russian Federation", Russia significantly lags behind on readiness for the digital economy from the top ten countries. The significant lag is explained by the improvement of the regulatory framework for the digital economy, the insufficiently favorable business environment and low level of digital technologies use by business structures.

With the use of digital technologies, agriculture is based on modern methods of agricultural products and food production; it provides an increase in labor productivity and a decrease in production costs. In the Russian Federation, more attention is paid to the development of state support measures in stimulating the development of digital technologies in the agroindustrial complex [3].

According to the Ministry of Agriculture of Russia, "the use of digital technologies in stimulating the development of digital technologies in the agroindustrial complex allows increasing the profitability of agricultural production through targeted cost optimization and more efficient allocation of funds. Any agricultural modernization program should be aimed at solving the main issue - to feed people. Since the real disposable income of the population in Russia is decreasing every year, the only way out is to reduce retail prices, and not by $10-15 \%$, but several times, while maintaining or even increasing the margins of the business of agricultural producers and at least not worsening the quality of products.

Experts consider two factors that make it possible to increase the consumption of agricultural products in Russia:

Firstly, the inaccessibility of modern means of mechanization and automation for the overwhelming majority of agricultural producers in Russia is the main reason for extremely low labor productivity and high unit cost. The transition from the model of selling agricultural machinery and automation equipment into ownership to the model of paying for their functions according to the actual volume or even the results of consumption, which is the basis of digital transformation, solves the problem of equipment availability and, consequently, increasing labor productivity. Since we start from a very low level of performance, it may well increase 3-5 times.

Secondly, digitalization, due to its end-to-end nature, allows information linking the needs of a particular end user and the capabilities of a particular agricultural producer, thus eliminating many unnecessary intermediaries, which now account for up to $80 \%$ of the retail price of a product. The introduction of the digital economy allows you to reduce costs by at least $23 \%$ while implementing an integrated approach.

Agricultural production has its own specific features that dictate the widespread use of digital technologies, like in no other area of the national economy, such as:

- participation in the technological process of living organisms, connection of operating modes of technical equipment with plants, animals and people, which leads to random changes in the dictating parameters of the production process and uncertainties in control and management in agricultural facilities;

- variety and complexity of production processes provided by digital technologies.

- distribution of the controlled parameters over a large area, the random nature of their nature.

-technological diversity of agricultural production and crops.

The main arguments in support of digital technologies of agricultural production are the need to fulfill the following problematic tasks associated with our lag behind the advanced countries of the world:

- increasing the quantity and quality of the crop;

- minimization of capital investment;

- reduction of labor intensity and increasing productivity of agricultural production;

- reduction of harmful effects on the environment;

- reduction of dependence on the human factor in agriculture and deviation in yield [4].

It is important to note that according to Rosstat and expert estimates:

- profitability of production in the agro-industrial sector is about $30 \%$;

- level of employment among workers in the agroindustrial sector in rural areas is comparable to the level of about 4.4 million people, with the stagnation of the number of workers in rural areas, of which only about 500 thousand are professionally trained workers;

- about 470 thousand agricultural units over 10 years old;

- decrease in yield deviation with the introduction of digitalization can be about $10 \%$;

- average service life of agricultural machines is about 15,000 operating hours [5];

One of the main stages of the digitalization of agriculture in Russia is the creation of mobile and stationary robotic platforms and complexes that perform various technological operations in agricultural 
production: in crop production, in animal husbandry, in greenhouses, in artificial intellectualized ecosystemsphytotrons, etc. The use of robotic platforms should provide an economic effect in the implementation of the entire technological process of agricultural production.

The results of work on the digital transformation of agriculture through the introduction of promising directions for increasing the efficiency of agricultural production management is the use of information systems based on geoinformation technologies. Such systems allow solving the following tasks:

- information support for decision making;

- planning of agrotechnical operations;

- monitoring of agrotechnical operations and the state of crops;

- forecasting crop yields and assessing losses;

- planning, monitoring and analysis of the use of technology.

For more efficient use, agronomic geoinformation systems should contain a multilayer electronic map of the economy and an attributive database of the history of fields with information about all agrotechnical measures [6]. Be sure to include mesorelief layers, information on the steepness of slopes and their exposure, microclimate, groundwater level, humus content in the soil, etc.

Agrotechnical planning includes the following types of work:

calculation of the potential and efficiency of personnel and land resources;

measurement of fields (for example, by detour along the contour with high-precision GPS equipment with a maximum accuracy of 1-3 cm);

drawing up the structure of sown areas and crop rotations in the format of a vector electronic map;

- analysis of the need for machinery and equipment;

calculation of the required amount of

fertilizers;

formation of the sequence of soil tillage operations, fertilization and protection means.

Planning carried out on the basis of the data of geographic information systems allows reducing or completely eliminating downtime in the event of a shortage of personnel or equipment, reducing the cost of agrotechnical operations per unit of cultivated area and improving yield indicators [7].

The yield forecasting system is based on the methods of monitoring the state of crops, taking into account the influence of natural and climatic conditions [8]. This technology allows tracking the dynamics of the crops development, growing conditions, determine the timing of their ripening and the optimal timing of the start of harvesting, conduct economic analysis at the minimum and maximum yield levels that are consistently possible for specific conditions. "Robotization" of production is especially relevant for large farms. Flying over fields, drones, using cameras and sensors, allow farmers to see in real time what each plant looks like, how crops mature and how the soil color changes.

"Agricultural" drones allow you to create electronic maps of fields in 3D format, calculate the Normalized
Difference VegetationIndex (normalized vegetation index) in order to effectively fertilize crops, inventory the work being done and protect farmland [8].

Digital technologies and automation of the maximum number of agricultural processes are included as a recognized need in the development strategy of the largest agro-industrial and machine-building companies in the world. Thus, digital technologies of agricultural production in the Russian Federation should provide for the next 3-7 years [8]:

- $\quad$ growth of crop and livestock production up to 1.5 times in 2025 ;

- $\quad$ improving product quality;

- $\quad$ decrease in the labor intensity of agricultural production by 1.5 times in 2025 ;

- $\quad$ cost and price reduction;

- $\quad$ energy and material consumption reduction;

- increase in productivity, for example, in crop production by 1.4 times; reduction of import dependence of agricultural machinery, their hardware and software; promotion of automation, robotization, intelligent machine technology.

The complex of digital technologies for agricultural production in Russia provides for the implementation of several key activities for the development and creation of a geoinformation monitoring system, the creation of an intelligent decision support system for agricultural producers in crop production, animal husbandry, greenhouses, artificial ecosystems, etc., the creation of intelligent robotic tools, comprehensive testing and approbation of the activities' results on the basis of regional agricultural complexes, staffing of digital agroindustrial production [9].

Separate blocks of this concept are intensively implemented in various constituent entities of the Russian Federation of digital approaches in agriculture, among which one can note Altai and Krasnodar Territories, Kursk, Lipetsk and Samara Regions, the Republic of Bashkortostan and the Republic of Tatarstan. The lowest rates are recorded in the Jewish Autonomous Region, Amur, Kirov, Kostroma, Magadan and Murmansk regions, Kamchatka and Primorsky Territories, the Kabardino-Balkarian Republic and the Karachay-Cherkess Republic.

The level of digital technologies of agricultural production in the regions was assessed according to such indicators as the approbation of pilot solutions and their replication, the full-function application of the Electronic Government and new digital technologies, amendments to regulations ensuring the implementation of the departmental project "Digital Agriculture", unification and application of centralized solutions, as well as the ability to connect already existing regional systems with a high level of development of IT technologies in agriculture [10].

Among the existing barriers to organizational, software, information and hardware support for the digitalization of agricultural enterprises in Russia, one can note: 
need for import substitution of component and instrument base, more than $70-80 \%$;

need to use a single software platform and exchange protocol between various software agents and structural units;

insufficient staffing of digitalization activities at the federal, regional, local levels and individual agricultural enterprises;

need to provide a stable high-quality navigation and cellular signal throughout the territory of the Russian Federation due to the large scale of territories and a variety of soil and climatic zones.

\section{Conclusion}

In the context of globalization and the deepening of inter-sectoral ties, agricultural production has become the basic link shaping growth trends for related industries; therefore, digital agricultural technologies are of the most significant importance for increasing the efficiency of production and processing of products.

It should be noted that the international political situation is pushing our country to significant changes in the agricultural sector. To do this, it is necessary to transform the agricultural sector and direct it to an innovative development path based on the digital economy. Digitalization is accompanied by the problem of localization of the target user group and the issue of the correspondence of digital solutions for various forms of agricultural enterprises. In digital technologies, there is a problem of localization of the target user group and the issue of the correspondence of digital solutions for various forms of agricultural. Digitalization and automation of the maximum number of agricultural processes is included as a conscious need in the development strategy of the largest agro-industrial and machine-building companies in the world.

Agricultural production is the most vulnerable business as it is highly dependent on weather and natural phenomena. Unlike traditional production in agriculture, you cannot structure all business processes in advance.

The digitalization of agricultural production in Russia should provide by 2025 :

- increase in production of crop and livestock products up to 1.5 times;

- $\quad$ increase in product quality;

- reducing the labor intensity of agricultural production by 1.5 times; reduction of costs and prices; reduction of energy and materials consumption, reduction of import dependence of agricultural machinery, their hardware and software, promotion of automation, robotization, intelligent machine technology.

The digitalization of agricultural production in Russia represents a higher level of digital integration, which affects the most complex organizational changes in business; their implementation can radically affect the profit and competitiveness of products and the company itself. On the way to digitalization of business processes in agriculture, there are many difficulties and even more questions.

\section{References}

1. D.R. Vakhitov, R.A. Latypov, Directions of digitalization of the world and domestic economy, in: Transformation of the national socio-economic system of Russia. Mat. of the $2 d$ Int. Sci. and Pract. Conf., pp. 192-196 (Moscow, 2020)

2. M.R. Shamsutdinova, M.A. Loseva, Development of the regional economy in conditions of depletion of natural resources, Economy and management: problems, solutions, 12, 78-82 (2012)

3. L.V. Zakharova, M.A. Antonova, International economic integration, in: Actual problems of quality management and competitiveness of products in modern conditions: mat. of the int. conf., pp. 22-23 (Kazan Cooperative Institute (branch) of Russian University of Cooperation, European University of Moldova, 2016)

4. M.R. Magdeeva, N.A. Utkina, Analysis of the investment attractiveness of the region (on the example of the Republic of Tatarstan), in: Actual problems of the development of tourism and the hospitality industry: Coll. of sci. papers of the $2 d$ Int. Sci. and Pract. Conf., pp. 51-54 (2019)

5. Retrieved from: http: //www.tadviser.ru/, http://www.radixtools.ru/

6. D.A. Mustashkina, T.K. Nikitina, Priorities of the Russian credit cooperative movement, in: The main directions of development of cooperation: experience, problems, prospects. Mat. of the Int. Sci. and Pract. Conf. in the framework of the annual Chayanov Readings, pp. 83-87 (2017)

7. T.S. Zagidullina, N.N. Zhilina, M.R. Magdeeva, Human capital as a determining factor in innovative development, Economics and Management: Problems, Solutions, 4(7), 25-29 (2018)

8. I.S. Starostin, E.S. Makarova, J.F. Nashirvanova, Ecology and economics: problems and solutions, in: Cooperation and entrepreneurship: state, problems and prospects. Coll. of sci. papers of the $3 d$ Int. Conf. of Young Scientists, Postgraduates, Students and Pupils, pp. 302-304 (2019)

9. Z.A. Godzhaev, A.P. Grishin, A.A. Grishin, Prospects for the development of robotic technologies in crop production, Tractors and agricultural machines, 12 (2015)

10. N.V. Karpova, D.A. Mustashkina, N.Y. Garafutdinova, Development of agricultural cooperatives in support of small agricultural enterprises, Scientific notes of the Russian Academy of Entrepreneurship, 18(1), 136-143 (2019) 